\title{
Correction to: Disrupted Development and the Future of Inequality in the Age of Automation
}

\section{Correction to:}

L. Schlogl and A. Sumner, Disrupted Development and the Future of Inequality in the Age of Automation, Rethinking International Development series, https://doi.org/10.1007/978-3-030-30131-6

The original version of this book was inadvertently published without the acknowledgement of the funder (Austrian Science Fund (FWF): PUB 676-Z). The book has been updated with the changes.

The updated version of the book can be found at https://doi.org/10.1007/978-3-030-30131-6

(C) The Author(s) 2020

L. Schlogl and A. Sumner, Disrupted Development and the Future of Inequality in the Age of Automation, Rethinking International Development series, https://doi.org/10.1007/978-3-030-30131-6_8 